\title{
Examining Fourth Year Mechanical Engineering Student Perceptions of Graduate AtTribute CoMpetencies: Year Three
}

\author{
Jillian Seniuk Cicek, Paul Labossiere and Sandra Ingram \\ Faculty of Engineering, University of Manitoba, Winnipeg, MB, Canada R3T 5V6 \\ umseniuk@myumanitoba.ca
}

\begin{abstract}
This paper describes the third year of a mixed methods explanatory case study to examine fourth year engineering student perceptions of the CEAB graduate attributes in the Mechanical Engineering program using a student exit survey and student focus group interviews. The purpose of this paper is to report students' perceptions of their graduate attribute competency levels and the program's graduate attribute strengths and weaknesses in a three-year continuum, supporting the findings with the data from three student focus group interviews. This investigation offers the faculty an understanding of its student engineering stakeholders' perceptions of how the CEAB graduate attributes are manifest in the Mechanical Engineering program. It will be used to provide feedback at instructor, program and faculty levels as the University of Manitoba's Faculty of Engineering furthers its efforts towards achieving a continuous cycle of improvement.
\end{abstract}

Keywords: CEAB graduate attributes; student exit survey; focus group interview; perceptions

\section{INTRODUCTION}

Perceptions are personal opinions, informed by the way that people view and interpret their own knowledge, learning experiences, goals, and expectations, and the level of autonomy that they have to direct instruction and learning [1]. How people react to their perceptions will vary their experiences, and thus responses [1]. Perceptions differ between respondents who have different primary functions within the educational equation. For example, as suggested by a long line of research, faculty and students often perceive educational efforts and methods differently [2]. Therefore, perceptions between different stakeholders, i.e., students, academic instructors and industry, are likely to be varied [1].

Due to the potential differences in perceptions in the educational equation, it becomes essential to understand all engineering stakeholders' perceptions regarding the CEAB graduate attributes, so that any misconceptions or differences can be revealed, common understandings found, and ultimately, curricula can be improved. This is especially important within scholastic environments, as the intended curriculum is not inevitably the learned curriculum [3][4]. Since students represent one of the engineering stakeholders integral to the accreditation and continual program improvement cycle, it is essential that their voices be heard.

\section{BACKGROUND}

This study was designed to investigate fourth year mechanical engineering students' perceptions of their graduate attribute competencies as developed within their engineering program using a student exit survey. The survey was devised to measure students' perceived aptitudes in regards to the required $\mathrm{CEAB}$ twelve graduate attributes, and students' perceptions of how well their engineering program prepared them in regards to the attributes. Additionally, the survey was intended to explore the relationship between students' participation in extra-curricular activities and their attribute competencies.

Originally, the study was conceived for the 2012-13 academic year. However, we realized the importance of building a longitudinal understanding of students' perceptions of their own aptitudes and of the program for the purpose of implementing a program feedback loop [5]. Therefore, we extended the study for two more years, and added a student focus group interview to our data collection methods as a means to qualitatively explore students' perceptions. The appendage of the focus groups also allowed us to further investigate the quantitative findings from the survey data, and to receive participant feedback on the survey instrument itself.

In this paper, students' perceptions of their graduate attribute competency levels, as well as their perceptions regarding the strengths and weaknesses of the Mechanical Engineering program and their own aptitudes in regards to the graduate attributes will be presented from the three-year continuum. Additionally, student suggestions for program improvement and survey implementation will be shared. Data are offered from both the student exit survey and the three student focus group interviews. 


\section{METHODOLOGY}

This study is a mixed methods explanatory case study [6][7][8], where quantitative survey data were collected and analyzed, from which emerged the protocol for the qualitative focus group interviews. It has an interpretivistic theoretical perspective and underlying epistemological view that truth is constructed through the interaction of the stakeholders with the researcher and the meaning-making activities of the research [9][10][11]. Quantitative and qualitative data analyses are sequential, with the qualitative findings informing the quantitative ones.

The Education/Nursing Research Ethics Board (ENREB), the governing research ethics board for the Faculty of Engineering at the University of Manitoba, approved the ethics application for this study. Purposeful sampling was used to identify and seek participation from three cohorts of fourth-year mechanical engineering students taking MECH 4860, who represented the class of mechanical engineering graduates of the 2012-13, 2013-14, and 2014-15 academic years, and who had the ability to contribute to the goals of the study [12][13].

\subsection{Student Exit Surveys}

The student exit survey was designed using Bloom's Taxonomy of Educational Objectives in the Cognitive Domain as the framework [14], and had two iterations as such [5]. To establish competency levels, six indicators for each attribute were created to reflect the six levels of the taxonomy: knowledge, comprehension, application, analysis, synthesis and evaluation. Students were asked to rate their proficiency for every cognitive level for each attribute. For the first year (2012-13), students were given a three-point scale; for the subsequent two years (2013-14, 2014-15), a five-point scale. Using the fivepoint scale, students were to consider for each indicator whether they were (i) not introduced to the skill/ability; (ii) introduced to the skill/ability, but that their performance was poor; (iii) introduced to the skill/ability, and their performance was adequate; (iv) introduced to the skill/ability, and their performance was good; or (v) introduced to the skill/ability, and their performance was excellent. Students were also asked to choose the three strongest and three weakest attributes in regards to the Mechanical Engineering program and with respect to their own knowledge, skills, behaviours and values [5]. (For explanation of the survey design changes, and exact wording of survey rating scale, see [5].)

The student exit survey was administered to three cohorts of fourth year mechanical engineering students in December of 2012, 2013 and 2014, at the conclusion of their Engineering Design course, MECH 4860. The instructor of MECH 4860 gave a manila envelope of surveys and a recruitment letter to each student team leader in the course. The letter explained the methodology and purpose of the research study, and described the survey instrument and instructions. The team leaders were asked to distribute the surveys to their team members. Completed surveys were collected by team leaders, placed into the unmarked envelope and left in the mechanical engineering office until after all course grades were officially entered. This was done to assure students' anonymity and prevent any conflict of interest vis-à-vis the course instructor, who is one of the principal researchers. The data from the surveys were analyzed using descriptive statistics.

\subsection{Student Focus Group Interviews}

Three qualitative focus group interviews with 11 participants were conducted over two years. All fourth year mechanical engineering students taking $\mathrm{MECH}$ 4860 over the 2013-14 and 2014-15 academic years were invited to participate. Two focus group interviews were completed in March 2014 with three students each from the 2013-14 cohort, and one focus group interview in March 2015 with five students from the 2014-15 cohort. The focus group interviews were designed to be semistructured, with the interview protocol for both years emerging from the analysis of the quantitative survey data. An inductive, constant comparative analysis method was used to code the data to uncover patterns and themes related to students' perceptions regarding the manifestation of the graduate attributes within the Mechanical Engineering program [15][16]. To improve the trustworthiness of the research, the researchers practiced member-checking, asking participants to review the transcript of their focus group interview, as well as the researchers' data analysis and resulting themes in the findings [12].

\section{FINDINGS}

With the exception of the second year of the study, when due to an administrative glitch the student exit survey was administered after the semester was over and students were difficult to contact [5], the response rate for the student exit survey has been high (see Table 1), which increases the rigor of the findings [12].

Table 1. Response rates for student exit survey, 20122015.

\begin{tabular}{|c|c|c|}
\hline YEAR & \# of Respondents & Response Rate \\
\hline $2012-13$ & $76 / 78$ & $97.4 \%$ \\
\hline $2013-14$ & $23 / 81$ & $28.4 \%$ \\
\hline $2014-15$ & $37 / 51$ & $72.5 \%$ \\
\hline
\end{tabular}

In addition to the student exit survey, 9 students from the 2013-14 and 2014-15 cohorts participated in one of 
three focus group interviews. Trustworthiness of the focus group data was increased by triangulating the findings of each focus group with the data from the other focus groups, as well as with the findings from the survey data [12].

\subsection{Perceptions of Program and Student Strengths and Weaknesses - Student Exit Survey}

On the exit survey, students were asked to rank what they perceived as the top three program strengths, and their top three strongest competencies in regards to the graduate attributes, and conversely, the top three program weaknesses, and their top three weakest competencies. Figure 1 illustrates the percent responses for the three years in which the student exit survey was administered. The graphs on the left represent program and student strengths and the graphs on the right depict program and student weaknesses.

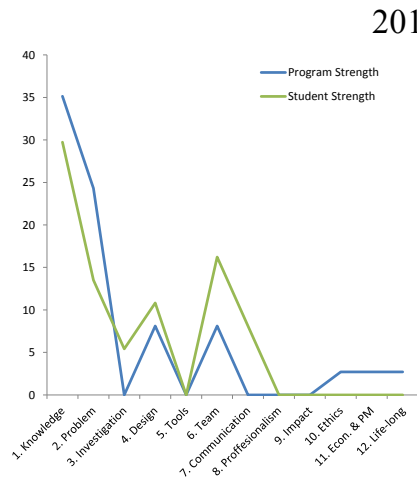

2014-15

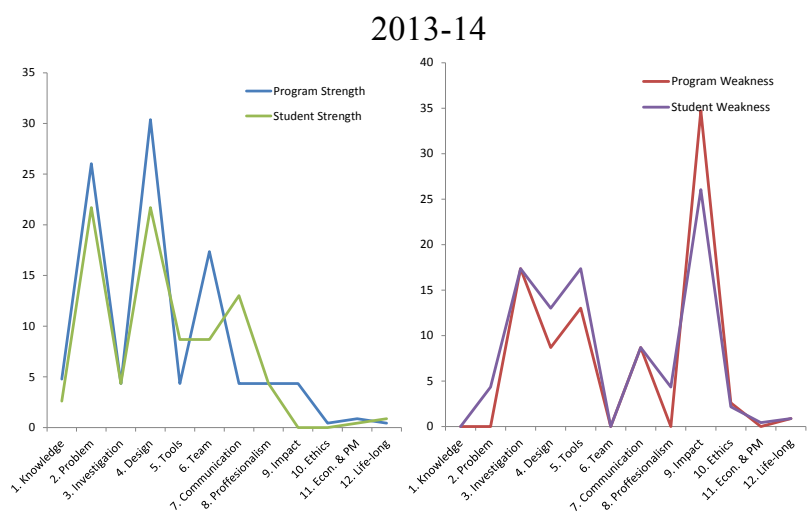

2012-13
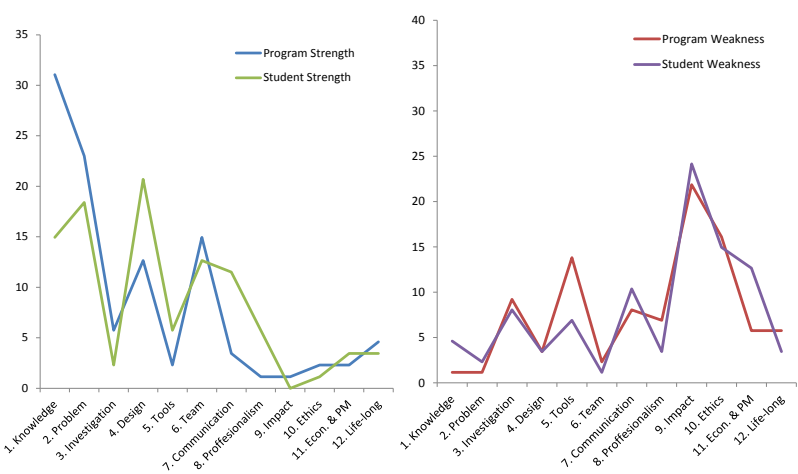

Fig. 1. Percentage of responses for the top perceived program and student strengths (left) and program and student weaknesses (right), 2012-2015.

Findings showed that over three years, Problem Analysis and Individual and Teamwork were the attributes that students perceived represented the top Mechanical Engineering program strengths, followed by A Knowledge base for Engineering and Design (see Table 2).

Table 2. Comparison of percentage of responses of the top three student perceived Mechanical Engineering program strengths, 2012-2015.

\begin{tabular}{|c|c|c|c|c|}
\hline $\begin{array}{c}\text { Program } \\
\text { Strengths }\end{array}$ & $2012-13$ & $2013-14$ & \multicolumn{2}{|c|}{$2014-15$} \\
\hline 1 st & $\begin{array}{c}\text { Knowledge } \\
\text { Base }\end{array}$ & Design & \multicolumn{2}{|c|}{ Knowledge Base } \\
\hline 2 nd & $\begin{array}{c}\text { Problem } \\
\text { Analysis }\end{array}$ & $\begin{array}{c}\text { Problem } \\
\text { Analysis }\end{array}$ & Problem Analysis \\
\hline $3^{\text {rd }}$ & Teamwork & Teamwork & Teamwork & Design \\
\hline
\end{tabular}

Students perceived that Problem Analysis and Individual and Teamwork were the top student attribute competencies, followed by Design (see Table 3). Therefore, with the exception of A Knowledge Base for Engineering, the top perceived program attribute strengths matched the top perceived student attribute competency strengths.

Table 3. Comparison of percentage of responses of the top three student perceived mechanical engineering student strengths, 2012-2015.

\begin{tabular}{|c|c|c|c|c|}
\hline $\begin{array}{l}\text { Student } \\
\text { Strengths }\end{array}$ & $2012-13$ & \multicolumn{2}{|c|}{ 2013-14 } & $2014-15$ \\
\hline 1st & Design & $\begin{array}{l}\text { Problem } \\
\text { Analysis }\end{array}$ & Design & $\begin{array}{c}\text { Knowledge } \\
\text { Base }\end{array}$ \\
\hline 2nd & $\begin{array}{l}\text { Problem } \\
\text { Analysis }\end{array}$ & \multicolumn{2}{|c|}{ Communication Skills } & Teamwork \\
\hline $3 r d$ & Teamwork & Tools & Teamwork & $\begin{array}{l}\text { Problem } \\
\text { Analysis }\end{array}$ \\
\hline
\end{tabular}

Findings showed that over three years, Impact of Engineering on Society and the Environment and Use of Engineering Tools were the attributes that students 
perceived represented the top two Mechanical Engineering program weaknesses (see Table 4).

Table 4. Comparison of percentage of responses of the top three student perceived Mechanical Engineering program weaknesses, 2012-2015.

\begin{tabular}{|c|c|c|c|}
\hline $\begin{array}{c}\text { Program } \\
\text { Weaknesses }\end{array}$ & $2012-13$ & $2013-14$ & $2014-15$ \\
\hline 1st & $\begin{array}{c}\text { Impact of } \\
\text { Eng. }\end{array}$ & Impact of Eng. & $\begin{array}{c}\text { Impact of } \\
\text { Eng. }\end{array}$ \\
\hline 2nd & Ethics & Investigation & Eng. Tools \\
\hline 3rd & Eng. Tools & Eng. Tools & $\begin{array}{c}\text { Econ. \& } \\
\text { Project M. }\end{array}$ \\
\hline
\end{tabular}

Impact of Engineering on Society and the Environment, followed by Ethics and Equity and Investigation, were perceived as the top student attribute competency weaknesses over three years. Thereby, Impact of Engineering on Society and the Environment was perceived as both the top program and top student weakness (see Table 5).

Table 5. Comparison of percentage of responses of the top three student perceived mechanical engineering student weaknesses, 2012-2015.

\begin{tabular}{|c|c|c|c|c|c|}
\hline $\begin{array}{c}\text { Student } \\
\text { Weaknesses }\end{array}$ & $2012-13$ & 2013-14 & \multicolumn{3}{|c|}{ 2014-15 } \\
\hline $1 \mathrm{st}$ & $\begin{array}{l}\text { Impact of } \\
\text { Eng. }\end{array}$ & $\begin{array}{l}\text { Impact of } \\
\text { Eng. }\end{array}$ & \multicolumn{3}{|c|}{ Impact of Eng. } \\
\hline 2nd & Ethics & \begin{tabular}{|l|l|} 
Invest. & $\begin{array}{l}\text { Eng. } \\
\text { Tools }\end{array}$ \\
\end{tabular} & \multicolumn{3}{|c|}{ Lifelong Learning } \\
\hline $3 r d$ & \begin{tabular}{|c|} 
Econ. \& \\
Project \\
Management \\
\end{tabular} & Design & Invest. & $\begin{array}{c}\text { Comm. } \\
\text { Skills }\end{array}$ & Ethics \\
\hline
\end{tabular}

\subsection{Average Perceived Graduate Competencies - Student Exit Survey}

Figure 2 illustrates the average perceived student competencies for all 12 graduate attributes for the three years that the survey was administered. Every attribute was rated in consideration of Bloom's Cognitive Domain: knowledge, comprehension, application, analysis, synthesis and evaluation. (Note that the scales are different between the 2012-13 offering, and the 2013$14,2014-15$ offerings due to the change in the rating categories [5].)

The highest perceived student graduate attribute competency for three years was Individual and Teamwork. The lowest perceived student graduate attribute competency for three years was Impact of Engineering on Society and the Environment. These are the same attributes that students' perceived as the top strengths and weaknesses within the program and in regards to their own aptitudes, which strengthen the reliability of the findings [12]. The upward and downward trends of the data over the three years are similar, with the exception of Problem Analysis, which increases in the third year, and Lifelong Learning, which shows a slight decrease in the second year.
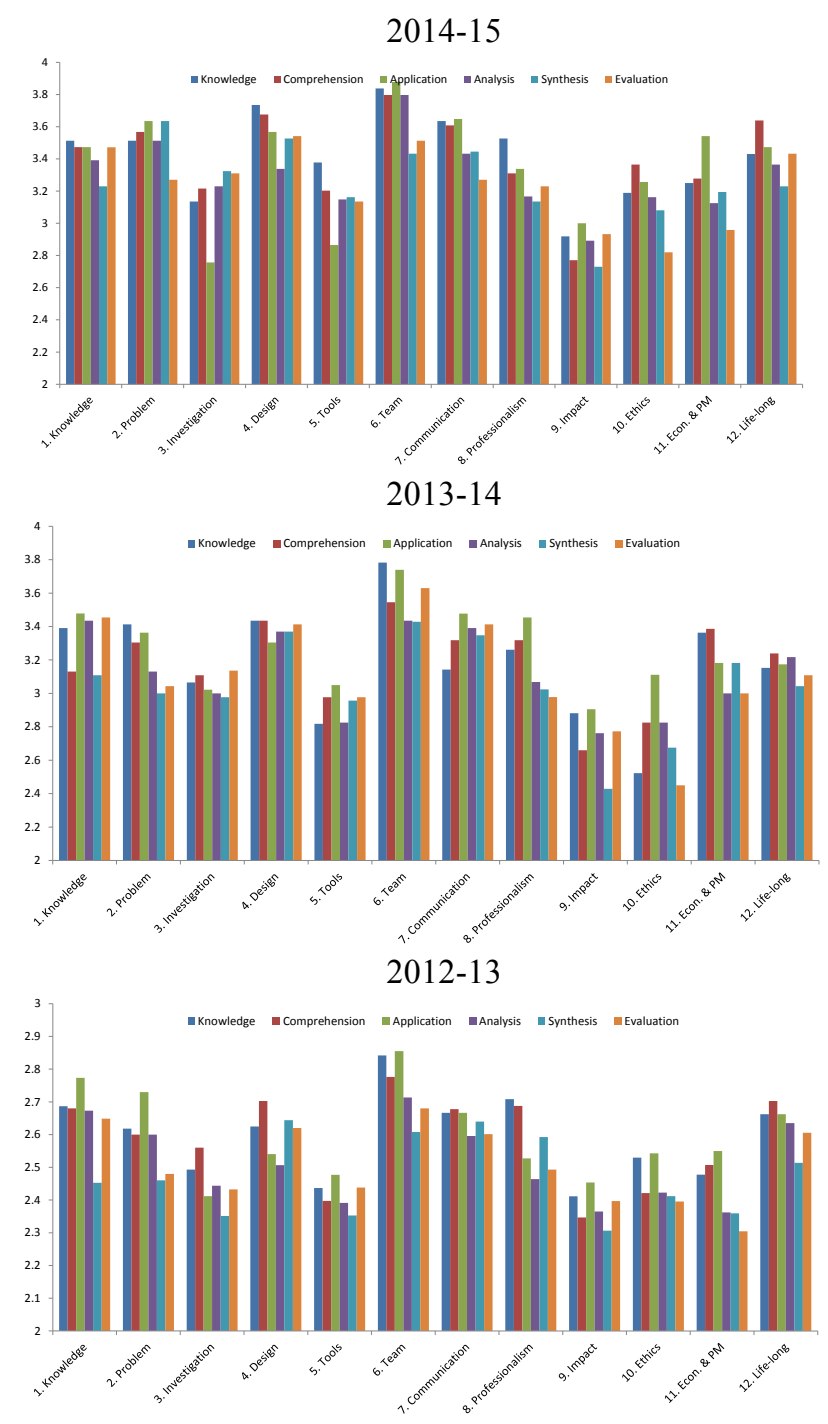

Fig. 2. Average perceived graduate competencies, 20122015.

Additional findings show that the cognitive domain, synthesis, was rated relatively lower for all three years than the other levels of the taxonomy in the attributes, A Knowledge Base for Engineering, Individual and Teamwork, Impact of Engineering on Society and the Environment, and Lifelong Learning.

\subsection{Perceptions of Program Strengths and Weaknesses - Student Focus Groups}

Analysis of the data collected from the fourth year mechanical engineering students who participated in the three focus group interview sessions over the 2013-14 and 2014-15 academic years indicated that students' 
perceived five common strengths in the Mechanical Engineering program: (1) engineering theory; (2) teamwork; (3) lifelong learning; (4) engineering projects; and (5) extracurricular opportunities (including the Co-op program). The weaknesses in the Mechanical Engineering program as perceived by the focus group participants included the lack of education on, or opportunity for: (1) professionalism; (2) ethics; (3) practical, hands-on knowledge and experience that connects theory to practice; (4) Finite Element Analysis (FEA); and (5) an education related to manufacturing, which is a Manitoba industry strength. Students also commented that although the design component of the program was good, it could be improved.

\subsection{What Students Would Like - Student Focus Groups}

Students would like more hands-on, practical engineering experience; more exposure to engineering tools, both software and hardware; peer evaluations for every group project; and an education in FEA.

\subsection{Student Suggestions for Program Improvement - Student Focus Groups}

Focus group student participants made several suggestions for program improvement. They are listed below, and in parenthesis, their connection to each graduate attribute is noted:

1. Optional workshops for specific tools or techniques (Use of Engineering Tools);

2. Mandatory Ethics seminars offered throughout the degree, with ethics lectures, discussions and guest speakers from industry (Ethics and Equity; Professionalism);

3. A reverse engineering design course (Design; Use of Engineering Tools);

4. Use of campus facilities to expose students to authentic examples of engineering, i.e., tour the university boiler room (Use of Engineering Tools);

5. A required paragraph in all design reports on the environmental impact of the design (Design; Impact of Engineering on Society and the Environment; Professionalism; Ethics and Equity);

6. A Manufacturing Process course with both technical and practical content, with machines available for use by all engineering students outside of class time (Use of Engineering Tools).

\subsection{Student Responses to the Exit Survey and Focus Group Interview - Student Focus Groups}

Generally, student focus group participants expressed that they were pleased to be asked their opinion about the
Mechanical Engineering program and their education, vis-à-vis both the exit survey and the focus group interview. In regards to the survey, some participants spoke of the satisfaction of doing a 'self-evaluation,' and they reflected with some surprise on all that they did learn in the program. Participants spoke of really enjoying the focus group, and the opportunity to discuss the program. They would like to see more students have, or take, that opportunity.

\subsection{Student Suggestions to Improve the Exit Survey - Student Focus Groups}

Generally, focus group participants suggested administering the student exit survey in class, so that all students completed it. They also recommended distributing it earlier, so that it did not coincide with the extremely busy end of the semester.

\section{DISCUSSION}

Findings showed in the data from both the student exit surveys and the student focus group interviews that students perceived Problem Analysis, Individual and Teamwork, and A Knowledge Base for Engineering as the strongest attributes within the program. Certainly, it is encouraging that two fundamental engineering technical attributes are highly rated for the Mechanical Engineering program. Furthermore, it is promising that Individual and Teamwork has also been rated consistently high by students in the data, particularly as it is one of the professional skills, which have been customarily shown in engineering education research to be more challenging to teach and assess than the technical skills $\quad[17][18][19][20][21]$ [22][23][24][25][26].

Interestingly, focus group participants considered Lifelong Learning a program strength, although it is also an attribute discussed as acutely challenging to teach and assess [26][27], partially due to the notion that it is more suitable to be assessed "a priori" [26]. Ironically, one focus group participant expressed this conception of lifelong learning being difficult to assess within the program: "I think the program actually prepares you very well for that [lifelong learning], it's just you don't realize it yet, because you don't have time to try it yet for the most part." What would be interesting and helpful would be to have students define lifelong learning, and identify where in the program they feel they are gaining the skills inherent in this attribute. Noteworthy is that the process of participating in the exit survey perhaps helped students display part of the aptitude inherent in lifelong learning, as they are required to reflect on their own learning. One participant stated in regards to the exit survey, “...I never really thought about going actually through them [the 
attributes], but once they were presented in front of me, it's like, oh yeah, I guess I did learn how to do that..."

Findings showed that overall, Impact of Engineering on Society and the Environment, Use of Engineering Tools, Professionalism and Ethics and Equity are the four attributes that students perceived as relatively weaker within the program. 'Relatively,' because although they have been shown to be the bottom attributes in data compiled over three years, they are still ranked above 2.2 on the 3-scale, and above 2.4 on the 5 -scale, which indicate that students on average still perceive that they have gained an adequate to good competency level for these attributes within the Mechanical Engineering program. That being said, these are important attributes to professional engineers, and it would be wise to investigate them within the program further. Recommendations to examine these attributes include: (i) mapping them in curriculum; (ii) exploring faculty/industry perceptions in regards to the importance of these attributes and their treatment within the curriculum; and (iii) determining students' definitions and expectations of these attributes. Recommendations for improvements include: (i) disseminating these data to teaching faculty within the Mechanical Engineering program so that they are aware of students' perceptions and can possibly incorporate them; and (ii) making deliberate changes to the curriculum to improve the manifestation of these attributes.

Interestingly, our data may be viewed in the context of the findings of a seven-year study conducted in the United States, where engineering graduates were asked to value each of the ABET attributes in relation to their professional careers. In the study, Passow found that regardless of the engineering discipline, graduates ranked teamwork, communication, data analysis and problem solving as the top used competencies (i.e., attributes) within their disciplines. The lowest ranked competencies were contemporary issues, design of experiments, and understanding the impact of one's work [28]. So although it is important to use the findings from our data to improve the program, it is also important to contextualize the findings. Two of the most important attributes within Passow's study are considered by students to be the top two attributes in the Mechanical Engineering program: Problem Analysis and Individual and Teamwork [28]. One of the lowest ranked competencies within Passow's study is also perceived as the lowest ranked attribute in our findings: Impact of Engineering on Society and the Environment [28]. That being said, our students' perspective is important, and they have let us know that "[If] You consider other professionals, dentistry, law, nursing... if you were to talk to the students they take their education way more seriously and they understand and respect their impact on society much more I think than some engineering people do...I don't think as students we're taught enough about how important it is to be a professional faculty and what that means to you and what that means is your responsibilities."

\section{NEXT STEPS}

The development of a set of graduate attribute rubrics by the Faculty of Engineering's Curriculum Management Committee (CMC) [29] has led to the redesign of the student exit survey. The rubrics are intended as an assessment tool for our programs and individual courses, and as a means of collecting data, which is an integral part of the CEAB accreditation requirements. As a result, we felt that it was crucial to redesign the student exit survey so that the indirect assessment data collected, namely students' perceptions, can be triangulated with the direct assessments of the graduate attributes within our courses and programs.

Consequently, we administered the 'old' version of the survey to only half of this year's fourth year mechanical engineering student cohort, and gave the 'new' version to the other half. Fifty of 51 students completed the new version of the survey. These data mark the beginning of a second cycle of program assessment to investigate how student engineering stakeholders perceive the manifestation of the CEAB graduate attributes in the Mechanical Engineering program. In the interim, the data from the preceding three years will be used to inform program improvement in order to close one assessment loop, and the new survey instrument will take its place in the effort to not only continually improve the program, but to improve the assessment tools that we use to inform these important changes.

\section{CONCLUSIONS}

The objective of this study to examine fourth year mechanical engineering students' perceptions of graduate attribute competencies in the Faculty of Engineering at the University of Manitoba has been achieved. It is clear that there are trends in the data over the course of the three years that this study was conducted. Faculty at the University of Manitoba can be quite confident that the Mechanical Engineering program is perceived by their students to be quite successful in their implementation of the graduate attributes, Problem Analysis, Individual and Teamwork, and A Knowledge Base for Engineering. On the other hand, the attributes Impact of Engineering on Society and the Environment, Use of Engineering Tools, Professionalism, and Ethics and Equity should be further scrutinized within the Mechanical Engineering curriculum to inform critical program improvements.

As researchers, it was an honour and a privilege to be witness to students' valuable insights in regards to their educational experience within the Mechanical 
Engineering program for the purpose of developing and improving its curricula for the benefit of all stakeholders. Students' perceptions will continue to be heard and explored at the University of Manitoba's Faculty of Engineering, as students are one of our vital stakeholders in our engineering programs.

\section{Acknowledgements}

The authors would like to thank the engineering students from the 2013-14 and 2014-15 academic years who willingly gave of their time to provide valuable feedback by participating in a student focus group interview. We also thank our 2014-15 mechanical engineering students, and all of our previous students, who responded to our exit survey. We are grateful to the members of our Curriculum Management Committee (CMC) for their continued support and encouragement, and to the University of Manitoba NSERC Design Chair for his support. This research study was funded by Jillian Seniuk Cicek's University of Manitoba Graduate Fellowship (UMGF) and Manitoba Graduate Scholarship (MGS).

\section{References}

[1] Effie Maclellan, "Assessment for learning: The differing perceptions of tutors and students," Assessment and Evaluation in Higher Education, vol. 26, no. 4, pp. 307-318, 2001. Available as of April 11, 2014 from http://strathprints.strath.ac.uk/2427/

[2] Matthew A. Holsapple, Donald D. Carpenter, Janel A. Sutkus, Cynthia J. Finelli, and Trevor S. Harding, "Framing faculty and student discrepancies in engineering ethics delivery," Journal of Engineering Education, vol. 101, no. 2, pp. 169-186, 2012.

[3] Brian Frank and Sue Fostaty-Young, "What can our students do: Year 2 of graduate attribute assessment at Queen's University," in Proc. CEEA Canadian Engineering Education Conf., CEEC11, Andy Fisher (ed.) (St. John's, NL; 6-8 June 2011), 6 pp., 2011.

[4] Maura Borrego and Jonte Bernhard, "The emergence of engineering education research as an internationally connected field of inquiry," Journal of Engineering Education, vol. 100, no. 1, pp. 14-47, 2011.

[5] Jillian Seniuk Cicek, Paul Labossiere and Sandra Ingram, "Examining fourth year engineering student perceptions of graduate attribute competencies: Year two," in Proc. CEEA Canadian Engineering Education Conf., CEEC14, Marjan Eggermont and Bill Rosehart (eds.) (Canmore, AB 8-11 June 2014), 9 pp., 2014.

[6] John W. Creswell, Qualitative inquiry and research design: Choosing among five approaches. Los Angeles, CA: Sage, 2013 (3rd ed.), 438 pp. \{978-1-4129-9530-6\}
[7] Maura Borrego, Elliot P. Douglas and Catherine T. Amelink, "Quantitative, qualitative and mixed research methods in engineering education," Journal of Engineering Education, vol. 98, no. 1, pp. 53-66, 2009.

[8] Matthew Wright, T. Froese and Susan Nesbit, "Canadian civil engineering and sustainable development competence," in Proc. CEEA Canadian Engineering Education Conf., CEEC14, Marjan Eggermont and Bill Rosehart (eds.) (Canmore, AB 8-11 June 2014), 1 pp., 2014.

[9] Aditya Johri, "Conducting interpretive research in engineering education using qualitative and ethnographic methods," in Cambridge Handbook of Engineering Education Research. New York, NY: Cambridge University Press, 2014, 763 pp. \{ISBN 978-1-107-01410-7\}

[10] Nancy Van Note Chism, Elliot Douglas and Wayne J. Hilson, Jr., Qualitative research basics: A guide for engineering educators. Rigorous Research in Engineering Education: Creating a Community of Practice, National Science Foundation, 2008, 69 pp. \{Report Number DUE0341127 $\}$ Available as of July 5, 2014 from http://crlte.engin.umich.edu/wpcontent/uploads/sites/7/2013/06/Chism-Douglas-HilsonQualitative-Research-Basics-A-Guide-for-EngineeringEducators.pdf

[11] Jennifer Turns and Cynthia J. Atman, "Concept maps for engineering education: A cognitively motivated tool supporting varied assessment functions," IEEE Transactions on Education, vol. 43, no. 2, pp. 164-173, 2000. Available as of April 24, 2014 from http://ieeexplore.ieee.org/xpl/login.jsp?tp=\&arnumber $=8480$ 69\&url=http $\% 3 \mathrm{~A} \% 2 \mathrm{~F} \% 2 \mathrm{Fiee}$ xplore.iee. $\mathrm{org} \% 2 \mathrm{Fxpls} \% 2 \mathrm{Fa}$ bs_all.jsp $\% 3$ Farnumber\%3D848069

[12] Jon, A. Leydens, Barbara M. Moskal and Michael J. Pavelich, "Qualitative methods used in the assessment of engineering education, Journal of Engineering Education, vol. 93, no. 1, pp. 65-72, 2004.

[13] Marcia Friesen, K. Lynn Taylor and M.G. (Ron) Britton, "A qualitative study of a course trilogy in Biosystems engineering design," Journal of Engineering Education, vol. 94, no. 3, pp. 288-296, 2005.

[14] Benjamin, S. Bloom (Ed.), Max D. Engelhart, Edward J. Furst, Walker H. Hill and David R. Krathwohl, Taxonomy of Educational Objectives: The Classification of Educational Goals. Handbook 1: The Cognitive Domain. New York, NY: Longmans, Green \& Co., 1956. 207 pp.

[15] Karen L. Tonso, "The impact of cultural norms on women," Journal of Engineering Education, vol. 100, no. 3, 217-225, 2011.

[16] Joseph S. Wholey, Harry P. Hatry and Kathryn E. Newcomer, K. E. (eds.), Handbook of Practical Program Evaluation. San Francisco, CA: Jossey-Bass, 2010 (3rd ed.), pp. 685 . 
[17] Carmen R. Zafft, Stephanie G. Adams and Gina S. Matkin, "Measuring leadership in self-managed teams using the competing values framework," Journal of Engineering Education, vol. 98, no. 3, pp. 273-282, 2009.

[18] Scott Jiusto and David Di Biasio, "Experiential learning environments: Do they prepare our students to be selfdirected, life-long learners?," Journal of Engineering Education, vol. 95, no. 3, pp. 195-204, 2006.

[19] Michael C. Loui, "Assessment of an engineering ethics video: Incident at Morales," Journal of Engineering Education, vol. 95, no. 1, pp. 85-91, 2006.

[20] Anne Colby and William M. Sullivan, "Ethics teaching in undergraduate engineering education," Journal of Engineering Education, vol. 97, no. 3, pp. 327-338, 2008.

[21] David H. Jonassen, Demei Shen, Rose M. Marra, YoungHoan Cho, Jenny L. Lo and Vinod Lohani, "Engaging and supporting problem solving in engineering ethics," Journal of Engineering Education, vol. 98, no. 3, pp. 235-254, 2009.

[22] Brock E. Barry and Matthew W. Ohland, "Applied ethics in the engineering, health, business, and law professions: A comparison," Journal of Engineering Education, vol. 98, no. 4, pp. 377-388, 2009

[23] Bugrahan Yalvac, H. David Smith, John B. Troy, and Penny Hirsch, "Promoting advanced writing skills in an upper level engineering class," Journal of Engineering Education, vol. 96, no. 2, pp. 117-128, 2007.

[24] James H. Hanson and Julia M. Williams, "Using writing assignments to improve self-assessment and communication skills in an engineering statics course," Journal of Engineering Education, vol. 97, no. 4, pp. 515-529, 2008.

[25] Jillian Seniuk Cicek, Paul Labossiere, and Danny Mann, "Surveying fourth year engineering student perceptions of graduate attribute competencies," in Proc. CEEA Canadian Engineering Education Conf., CEEC13, Michel Perrier and Sylvie Dore (eds.) (Montreal, QC; 17-20 June 2013), 7 pp., 2013.

[26] Larry J. Shuman, Mary Besterfield-Sacre and Jack McGourty, "The ABET "professional skills" - can they be taught? Can they be assessed?," Journal of Engineering Education, vol. 94, no. 1, pp. 41-55, 2005.

[27] R.W. Brennan, M. Eggermont, W. Rosehart, A.K. Deacon, N. Larson, and T.A. O'Neill. Assessing life-long learning in a first-year design and communication course. Proceedings of the Canadian Engineering Education Association Conference (CEEA14), 4 pp. Canmore, AB. June 8-11.

[28] Honor J. Passow, "Which ABET competencies do engineering graduates find most important in their work?", Journal of Engineering Education, vol. 101, no. 1, pp. 95118, 2012.
[29] Jillian Seniuk Cicek, Sandra Ingram, Nariman Sepehri, J.P. Burak, Paul Labossiere, Danny Mann, Douglas Ruth, Anne Parker, Ken Ferens, Norma Godarvi, Jan Oleszkiewicz, and Aidan Topping. "Rubrics as a Vehicle to Define the Twelve CEAB Graduate Attributes, Determine Graduate Competencies, and Develop a Common Language for Engineering Stakeholders," in Proc. CEEA Canadian Engineering Education Conf., CEEC14, Sean Maw and Marjan Eggermont (eds.) (Canmore, AB; 8-11 June 2014), 6 pp., 2014.

\section{APPENDIX A: STUDENT EXIT SURVEY FOR THE 2013-14, 2014-15 ACADEMIC YEARS}

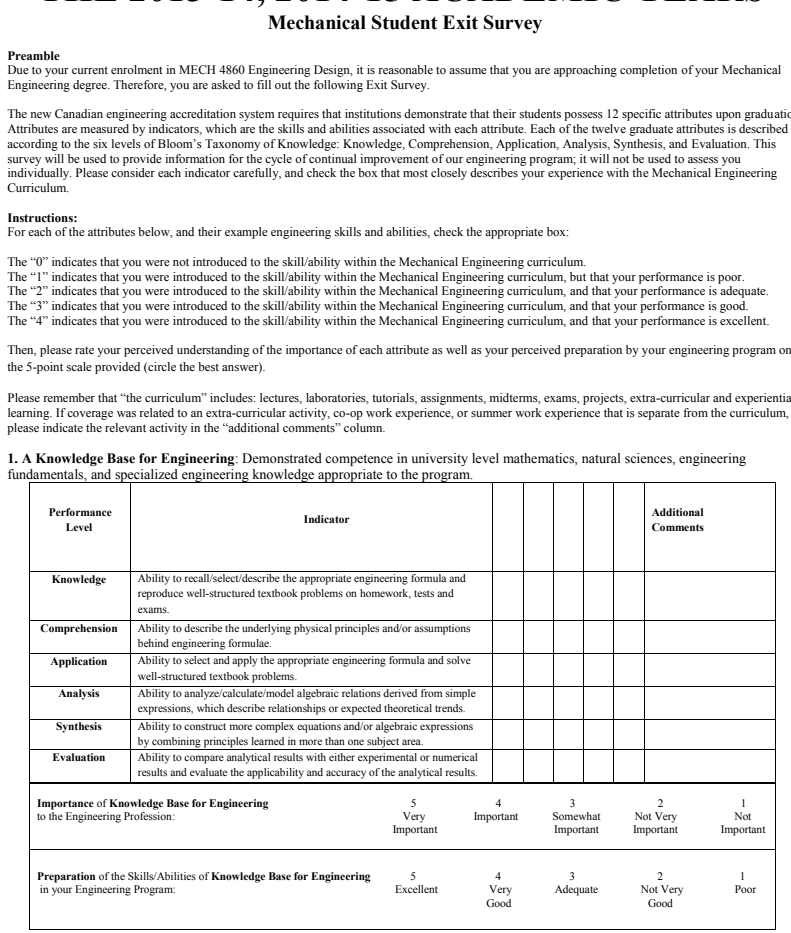

